\title{
THE ROLE OF THE MEDIA IN THE AFFIRMATION OF THE CULTURE OF FOOD SAFETY
}

\author{
Željko Bjelajac ${ }^{1}$, Aleksandar M. Filipović ${ }^{2}$ \\ *Corresponding authorE-mail: zdjbjelajac@gmail.com
}

A R T I C L E I N F O
Review Article
Received: 01 May 2020
Accepted: 24 May 2020
doi:10.5937/ekoPolj2002609B
UDC 663/664:658.562.47]:659.3

Keywords:

Food safety, food contamination, foodborne diseases, food safety culture, mass media

JEL: I12, L66, L82, Q53

\section{A B S T R A C T}

Abraham Maslow's theory is one of the best-known and oft-cited theories in the West. It is known as a theory of the hierarchy of needs. By this theory, human needs are hierarchically organized in five levels. The hierarchy is depicted as a pyramid, with the largest, most basic needs at the bottom, and the highest needs, such as selfactualization on top. It is understood that physiological needs are at the first level, such as needs for air, water, food... The physiological needs of an organism are basic human needs, and their fulfillment is a basic precondition followed by the needs of a higher order. Healthy life habits such as a good diet contribute to physical, mental, and emotional health. Their influence can be far-reaching, regardless of age, gender, or physical capabilities. Education accompanied by a steady application of current dietary knowledge allows us to consciously influence life processes in our organism. Mass media has to take the leading role in the promotion of food safety culture, while not considering only technical questions.

(C) 2020 EA. All rights reserved.

\section{Introduction}

Today it is more than ever clear how much safe food is important for our survival. Generally accepted practices which were created to provide safety of food for human consumption are not efficient enough. It is hard to say that there is absolute reliability in the chain of growing, processing, preparing, selling, and/or catering food. The human factor is undoubtedly responsible for the fact that nearly one of 10 people in the world

1 Željko Đ. Bjelajac, Ph.D. Full Professor, University of Business Academy, Faculty of Law for Commerce and Judiciary, Geri Karolja Street no. 1, 21000 Novi Sad, Republic of Serbia, Phone: +381644628967, e-mail: zdjbjelajac@gmail.com, ORCID ID https://orcid.org/00000003-4953-8779,

2 Aleksandar M. Filipović, Ph.D, Assistant Professor, University of Business Academy, Faculty of Economics and Engineering Management, Cvećarska Street no. 2, 21000 Novi Sad, Republic of Serbia, Phone: +381652607607, e-mail: sasha.filipovic@gmail.com, ORCID ID https://orcid.org/0000-0002-1097-2079 
get ill every year by consuming food processed or prepared in an unhygienic way, according to estimates of the WHO.

The contamination of food is extraordinarily complex and can envelop several contaminating substances simultaneously. The modern man, who is in a specific disharmony with nature, uses very frequently and negligently many chemical substances in the application of modern agrotechnical means, with intent to increase yields, quality, and protection of food from pests. At the same time, a significant number of substances reach food from the polluted environment (soil, water, or air). Accumulation of chemical substances and other harmful agents in food (pathogenic microorganisms, radioactive substances), leads to frequent pollution with multiple harmful effects on humans and animals. We can outline several types of contamination by the nature of contaminating matters: chemical contamination, radioactive contamination, biological contamination, and physical contamination.

Mass media routinely subjugate questions of food safety, complaints from consumers and their associations, and sometimes obvious results of inspections to their interests and vast profits from paid advertising by multinational corporations. Dedication to public health is secondary. Because of such practice, a large number of people in the world have problems with obesity and comorbidities, such as diabetes or heart diseases. So-called fast food with a large number of calories, along with consumption of energy drinks and soft drinks, contributes to the accumulation of lipids, which can be devastating for the human organism. Such a strong influence of mass media on consumers must be diverted and envisioned to help to organize and to strengthen of positively sustainable and mature food safety culture. In that way, together with responsibility ethics, buyers/consumers, the environment, and most importantly, the lives of people and coming generations can be effectively protected. If consumers use food that is unsafe, it may lead to deterioration of health of consumers, leading to increasing economic costs for medical treatment, payment, security, absence from work and the like (Bjelajac et al, 2013).

Therefore, food safety culture is not a declarative topic, but an essential question of choice for the betterment of civilization. It includes the application of food safety standards, dedication of management through a vision of values, responsibility, adaptability, and consistency in the domain of human dignity. The basic goal of this paper is to define dimensions and critical content of food safety while stressing the necessity of the development of healthy food safety culture.

\section{Methodology}

In writing of this paper the following methods were used: analysis, for defining the factors of contamination of food, to define the terms that influence the integrity of food, the terms that are factors of food safety culture, the terms that are factors of media systems: descriptive method was used for describing the roles of various groups of factors that influence the state of affairs that are the subject of this paper; media content analysis method was used in the section about the role of media in affirmation 
of healthy dietary choices; while the method of analysis of primary and secondary sources was used in gathering and interpretation of statistical data related to health disorders caused by contaminated and unhealthy food. The normative method was used in the description of certain legal regulations that tackle the effects the consumption of certain foods has on human health.

\section{Food contamination}

Under the term of food, all that is used for eating or drinking in a processed or raw state is implied. Food includes spices, colors, and all other substances (additives) that are added to food because of conservation, enrichment, or improvement of organoleptic attributes. Food can be plant-based (cereals, fruits, vegetables), animal-based (meat, fish, eggs, milk, etc.), mineral-based (table salt), synthetic (additives) (Jugović et al, 2017). In the total process of food manufacturing, in one or more phases, contamination of food used for human or animal consumption inevitably occurs, and depending on the phase or environment where the phases take place, food is exposed to contaminants to a larger or a lesser degree. It is understood that if the environment where food manufacturing takes place is more polluted (urban areas, industrial zones, etc.) the contamination risk is larger. Also, in environments where the contamination risk is higher food becomes polluted from several different sources, which poses an additional problem and health hazard. The transformation of rural areas to industrial also adds to the risk of pollution. For instance, in Serbia, annually between 6,000 and 30,000 hectares of agricultural land "disappear" due to urbanization, infrastructure construction and excavation sites (Počuča, Drašković, 2015).

By nature of contaminating matters, we can identify chemical contamination, radioactive contamination, and biological contamination (Jugović et al, 2017), while many scholars add another contamination category, the physical contamination of food.

Chemical contamination occurs by using chemical substances in the manufacturing process. The main chemical contaminants of food are additives, sweeteners, conserving agents, colors, pesticides, heavy metals (Jugović et al, 2017). The origins of chemical contaminants are various from the field to plate, namely soil, environment, disinfection byproducts, personal care products, air, water, and packaging material. Chemical contaminants inhibit almost all the mass-produced everyday use products such as disinfectants, plastics, detergents, deodorants, pesticides, and so on (Rather et al, 2017). Here we shall stress that the chemical contamination usually comes with intent, whether to increase quality and durability, whether to improve taste or color, which means that the greatest deal of this type of contamination could be avoided.

Radioactive contamination of food occurs due to the accumulation of radioactive elements on surfaces or withing solid, liquid, or gaseous matters where their presence is undesirable. Radioactive contamination can occur through natural radioactive contaminants or by radioactive products of human activity. In Serbia there are evident negative consequences due to the NATO bombing, and the use of depleted uranium 
ammunition and contaminated land has caused an increase in the number of cancerous diseases (Bjelajac et al, 2017). We shall also say that there is the widespread practice of sterilization of food by irradiation, which began in the second half of the 20th century, and is used in more than 60 countries in the world, but it does not cause radioactive contamination of food.

Biological contamination occurs when food comes into contact with chemically harmful matters through biological agents, meaning living organisms. Agents of biological contamination are insects, mold, parasites, viruses, and bacteria, which contaminate food in various ways. Generally, the biological contamination of food can occur in any phase of the life cycle of food, depending on the biological agent that contaminated the product. Insects and parasites usually contaminate food during cultivation, while bacterial contamination most often occurs by improper storing of food. A working hypothesis of the origin of the COVID-19 pandemic is that the virus infected a person who handled the meat of the infected animal and sold it to the consumer. We can see that the consequences of biological contamination of food can be disastrous - from destroyed crops and economic damage due to harmful activity of insects and parasites, poisoning caused by bacteria-contaminated food, to pandemics of infectious diseases.

Physical contamination of food occurs unintentionally - by mistake, lack of attention, or defective equipment for manufacturing, preparation, or storage of food. It implies the presence of physical objects in food, such as metal, glass, plastics, insects, nails, etc. The danger for the human organism from physical contamination of food varies depending on the contaminant, but it can cause serious injuries or poisoning.

According to the World Health Organization, the frequency of food poisoning in industrialized countries in the past ten years has been between 10 and 15 percent per year, while the incidence of milk and dairy products poisoning is estimated at around five percent per year (Bjelajac et al, 2017).

Figure 1. Global burden of foodborne diseases

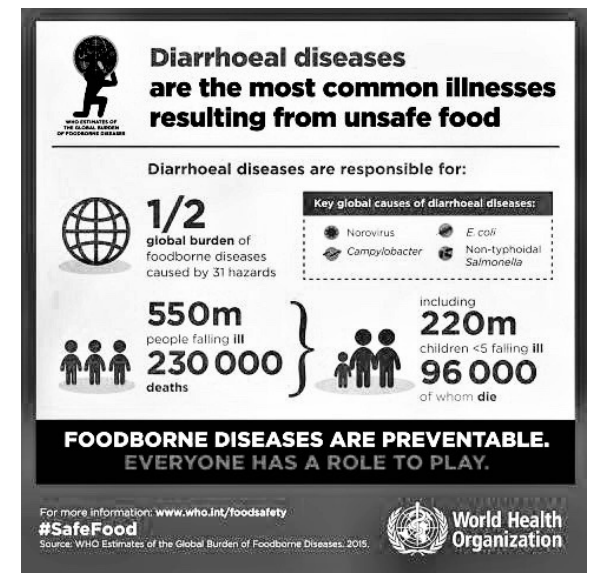

Source: The World Health Organization, 2015 
The Institute for Public Health of Serbia, in its annual report on the safety of food and bottled water in the Republic of Serbia for 2018 states that 7,976 samples of food were tested for chemical contaminants. It was determined that 176 samples contained physical and chemical contaminants. The majority of contaminated samples were contaminated by a high content of additives and increased content of nitrates. Additional 7,523 samples were tested for microbiological contamination. Microbiological contamination was determined in 38 samples. The most frequent reasons for microbiological contamination were the presence of mold, yeast, an increased number of colony-forming aerobic bacteria (Institute for Public Health of Serbia, 2018).

Table 1. Results of testing of food for chemical and microbiological contamination in Serbia in 2018

\begin{tabular}{|l|l|l|c|}
\hline \multicolumn{1}{|c|}{ Type of test } & $\begin{array}{c}\text { Number of } \\
\text { tested samples }\end{array}$ & $\begin{array}{c}\text { Number of } \\
\text { contaminated samples }\end{array}$ & $\begin{array}{c}\text { Percentage of } \\
\text { contaminated samples }\end{array}$ \\
\hline Chemical contamination & 7976 & 176 & 2,2 \\
\hline Microbiological contamination & 7523 & 38 & 0,5 \\
\hline Total & 15499 & 214 & 1,4 \\
\hline
\end{tabular}

Source: Institute for Public Health of Serbia, 2019

Still, in some cases, food that is not contaminated is not necessarily beneficial for health, on the contrary. Food can contain very large amounts of sugars or fats and not enough nutritive value, so the consumption of such food can lead to health problems, disorders, and diseases. While the developing countries are more hit by the harmful effects of contaminated food, developed countries are more hit by disorders and diseases caused by mass consumption of unhealthy food, such as obesity or diabetes. According to the data from American Centers for Disease Control and Prevention (CDC), the prevalence of obesity in adults in the USA was $42,7 \%$ in 2018, and that the share of obese persons grew from $30.5 \%$ to $42.7 \%$ in the period $2000-2018$, while the prevalence of severe obesity grew from $4.7 \%$ to $9.2 \%$. (Centers for Disease Control and Prevention, 2018). In addition to being a health problem, obesity caused by the consumption of unhealthy food poses an economic problem as well. The estimated annual medical cost of obesity in the United States was \$147 billion in 2008 US dollars (Finkelstein et al, 2009). Additionally, obesity raises the risk for morbidity from hypertension, dyslipidemia, type 2 diabetes, coronary heart disease (CHD), stroke, gallbladder disease, osteoarthritis, sleep apnea and respiratory problems, and some cancers. Obesity is also associated with increased risk in all-cause and CVD mortality (Jensen et al, 2014).

\section{The Importance of Food Safety Culture}

A simple answer can be given to question what food safety culture is. That is a culture where all the individuals involved in the chain of producing and distribution of food (owners, managers, employees) reason and act in the spirit of standards that the food they produce or serve must be safe in their everyday work activities. The food safety culture is imperative that quality products must be safe for consumption, and food safety must be undoubtedly the main priority. 
Foodborne diseases are a major public health problem worldwide. In Australia, approximately $25 \%$ of gastroenteritis cases were caused by contaminated food, and in 2010, 4.1 million foodborne gastroenteritis cases occurred. In 2010, contaminated food was estimated to be responsible for 30,840 gastroenteritis-associated hospitalizations, 76 associated deaths, and 5,140 non-gastrointestinal illnesses. (Kirk, et al, 2014). Therefore the representation of strong food safety culture makes people understand the importance of action in that direction. Minding that obligation always starts with the leading positions in the company management, and ends with the last link in the chain. Good food safety culture protects the consumers from foodborne diseases, preserves the reputation of certain brands, and protects the business from financial losses.

Figure 2. Elements of Food Safety Culture



\section{$\mathbf{N}$}

Source: adapted from Wright, Leach, 2013, Nvolve Group

Safety culture within an organization is attributed to the values of both individual employees and the business as a whole. The success of an organization's safety program is based on trust and a shared vision of importance surrounding safety for the entire organization. Developing a Food safety culture has become a key focus within the food manufacturing industry in recent years. Companies are investing more time and money into food safety as it has a direct impact on auditing success and the company's bottom line. Elements of food safety culture are (Nvolve, 2017):

1. Business priorities - The extent to which an organization prioritizes food safety and their overall attitude regarding food safety.

2. Risk perceptions - The organization's perception and understanding of the risks associated with food safety. 
3. Perception of food safety procedures - The organization's perception of the effectiveness and validity of food safety regulations.

4. Ownership of food safety - The level of responsibility that an organization accepts in relation to food safety.

5. Competence - The level of understanding an organization has regarding risk management procedures.

6. Leadership - The level of commitment that management has regarding food safety.

7. Employee involvement - The level of commitment the wider organization has toward food safety.

8. Employee communications - The level of communication across the organization and the freedom for employees to challenge procedures

We can see the importance given to the level of employee communication in the organization. Companies that have developed food safety culture permanently manage food safety training, and never consider it a routine exercise meant only to meet certain protocols. On the contrary, they do it because such an approach is an integral part of their sensitive work with food. Developed companies have advanced technologies at their disposal, so they can provide information on procedures used to maintain food safety to clients and/or regulators electronically.

We shall also have in mind the growing market for organic food, which is by definition produced without the use of chemicals than can end up contaminating food, such as pesticides, additives, etc. Consumers attach greater importance to these products especially in the food segment. The results of numerous studies confirm that the growth rate of organic foodstuffs by far exceeds the overall growth rate of the food market (Končar et al, 2019). Quality food is also of importance for overall tourism attractiveness, and it is a part of the basic tourism product (see: Vuković, 2018). In a study of satisfaction of hotel guests in Serbia, those whose motive for stay was business gave lower grades to selection of food and beverages in the hotels than those whose motive was tourism (Marinković, Sekulić, 2016), which means that in order to begin using of strategic potentials of our country, we shall cater both to food markets and consumers and visitors, whether for business or for leisure, but also by adding an endemic component in the tourism product we offer, and that is our local food and beverages, but per food safety and quality standards and procedures.

On one side, in our contemporary digital and integrated world, consumers are more aware of food safety than ever. Information on the quality and reputation of food brands is available by a one-click web search. On the other side, consumers are aware of the risks of unsafe food as well. They are concerned about the quality of food and import control measures. Mass media contribute to total confusion as they do not promote the companies with a strong food safety culture that uses these positive results of their work not only as a competitive advantage but for the good of mankind as well. 


\section{Mass media and affirmation of healthy dietary choices}

According to Lorimer (1998), mass media are a separate set of activities with primary, non-derived function to identify or construct reality. Here we shall make a distinction between mass communication and mass media, and say that mass communication is a much broader term, and that mass communication is not necessarily done through mass media, but that mass media perform the function of mass communication. This century and its most recent decade were marked by ascension of the Internet and social media among the most significant means of mass communication, slowly pushing out the print media. In addition to basic content, mass media publish or broadcast, advertising is also particularly important for our study, so the influence of media on the affirmation of food safety can be divided into two categories:

- Influence through basic media content (articles, shows, reports, audio, and video clips, etc.)

- Influence through advertising content

When discussing media content, we encompass both print and electronic media. With print media, a very important role belongs to lifestyle magazines whose target audience are generally women, which represent an important source of information about nutrition health. These magazines often contain recipes, but few contain any information on food safety, and where information is available, it is brief and inadequate (Griffith, Price, 1994). In the era of information oversaturation, unchecked information is often published, so lifestyle magazines sometimes promote food and supplements whose nutritional value and influence on human health are not confirmed. This happens very often on social media, where influencers promote such products in the form of paid advertisements, with no one trying to check the validity of information because the profit is the motive for both the advertiser and the media or those who perform the function of the media. Print media that survived the advent of the Internet and migration to digital and online were able to do that basically because of their quality and credibility built over decades of work. Therefore, they have a bigger responsibility to provide enough relevant information about safety, quality, and nutritional value of food to their readers.

Electronic media were the ones that significantly increased the audience and the reach. First the radio, then the television, followed by the Internet which is a platform for what we call the new media - portals, blogs, podcasts, social media - not only encompassed the existing media audience but reached and created a new one by the development of technical capacities for their use. Electronic mass media have the greatest capacity for identifying and constructing realities. That makes their influence immeasurable and generally uncontrolled - since the audience grows together with the number of available content - which leads to mass non-critical acceptance of opinions communicated by the media, whether through basic program contents or advertising. Both the television and the new media that broadcast video content have the potential to inform, and then to promote values of food safety culture, not only through culinary or agricultural shows but values embedded in the rest of their programming, especially because there is a social consensus that the quality and 
safety of food is a shared value of the mankind. The medium of television possesses advantages over the other media forms for the presentation of food hygiene information. Food hygiene is partly knowledge-based and partly skills-based, and television can be especially suited to demonstrating good hygiene skills and practices. Furthermore, the presenters are often people of "prestige" who have popular appeal and for whom the public have a liking. (Griffith, Price, 1994). We have a similar situation in the new media, which created thousands of new media personalities in whom the audience has trust. Compared to their power and potential for positive influence, neither traditional nor new media do not do as much as they could in giving all the relevant information about the hygiene, safety, and quality of food, nor in promotion of food safety culture.

A significant part of a total message broadcasted by mass media is done through advertising. Advertising is an invention of crucial importance for capitalist societies, and it is embedded in the very foundation of commercial mass media, as it allows the production and distribution of information and entertainment for a large segment of the population at a very low cost for the consumer (Lorimer, 1998). In the past, the effect of the product, and satisfaction of consumers, was supplemented by ads to increase or maintain the sales, but the advertisers now create new markets by launching new products. An advertiser creates a need and then convinces us that the product fulfills that need (Lorimer, 1998). Advertising has several forms - from print ads or advertising spots, PR articles, and social involvement of the advertised brands, to the physical placement of products in media contents.

Figure 3. Total revenue by publisher and magazine by type (subscription, sales, advertising)

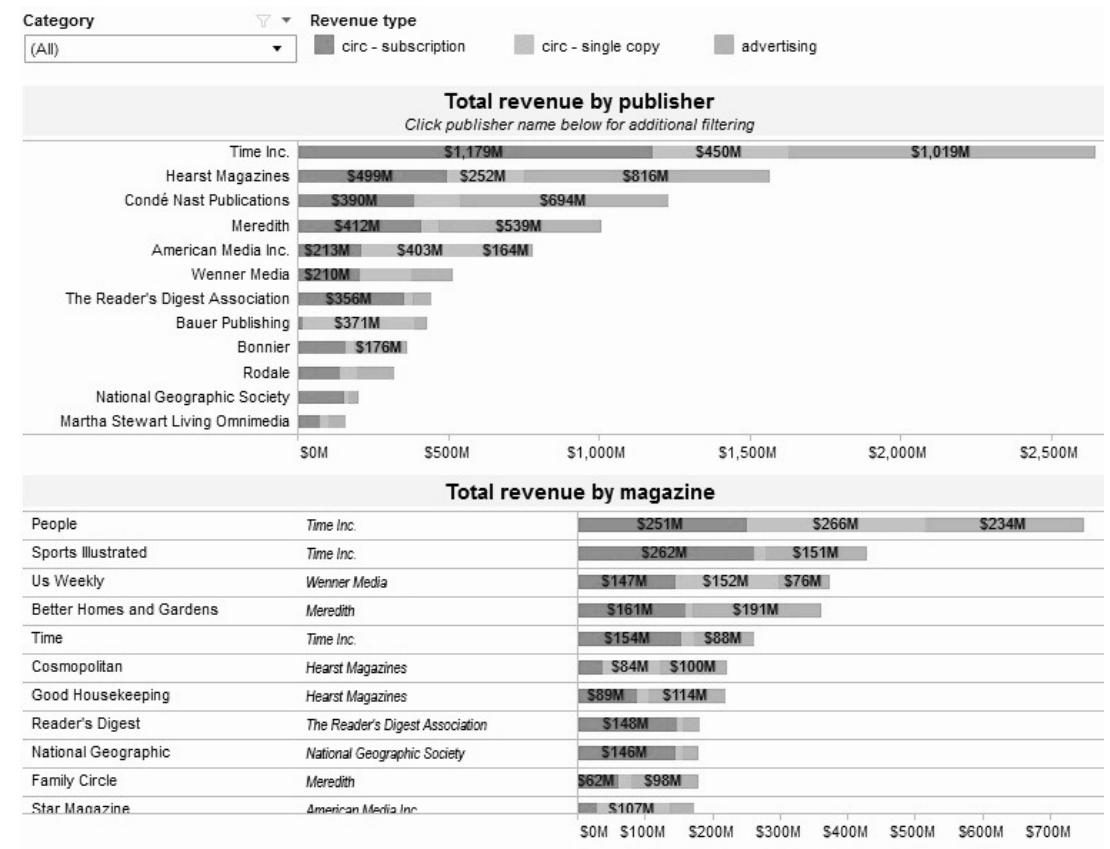

Source: Spyglass Intelligence, 2020 
It is a fact that the media will advertise anything that is not explicitly forbidden and can bring revenue, and that fact is unchangeable. Why we are bombarded with "cannot miss" sandwich and pizza deals chasing us to our houses and even while reading the newspaper or watching the television? The answer is quite simple. We are obviously being conditioned to look at food as entertainment (Alkharfy, 2011). Food advertisers often use techniques known to enhance the appeal of advertisements to children and known also to mediate positive responses to the brands being promoted (Gunter, 2016). Before, tobacco manufacturers and ad agencies were unscrupulous in finding ways to improve the sales by advertisements, so the ads for cigarettes often included the depiction of children who smoke. By strict regulation of tobacco products, not only their advertisement was forbidden, but brand names and packaging of tobacco products were changed, with a clear warning of their harmfulness, which in certain countries include graphic depictions of diseases smoking can cause. So what is the state of affairs with food whose contents also cause serious health disorders? In 2016 the UK government decided to impose an additional levy, to take effect in 2018, on producing and importing soft drinks containing added sugar. A levy on soft drinks contributes to the government's plans to reduce childhood obesity by removing added sugar from soft drinks and encourages producers of added sugar soft drinks to reformulate their products to reduce the sugar content to encourage consumers of soft drinks to move to healthier choices (HM Revenue \& Customs, 2016). In addition to obvious health benefits, the UK government expects an income of around 1,5 billion pounds in a threeyear period (2018-2021). Additionally, retailers must display the information about the amount of added sugar as well as nutritive values of a product on their shelves, so the consumers would have clear information.

\section{Discussion}

In the past, since the dawn of mankind, to the modern age, food represented only sustenance to the people, which shall meet basic nutritional needs and provide survival. The choice of food was narrow and came down to whatever people were able to get - by hunting, fishing, collecting, or farming. In that age, the life expectancy was significantly shorter than today for both men and women, and it was in part because of the quality and diversity of consumed food or drinking water. By civilizational progress, we reached an understanding of the influence of consumed food on health, quality of life, and life expectancy. As certain foods or products harm health, some others have a beneficial effect, even so, they help in the treatment of some diseases, and in any case improve the general health of an organism, from digestion to immunity. That means that people once ate and drank what they had at disposal, while today they can consume food following their preferred diet and the results they aim to achieve, whether they are in a sense of health, aesthetics, or identity through diet (vegans, etc.).

Still, in that multitude of choices, the modern man often goes for the simplest solutions. The typical reason for that is the acceleration of modern life, where people often do not have time for a healthy meal full of necessary nutrients. People then turn to fast food - 
whether they are employees, students, or pupils. Everything is known about deficiency of fast food, which means that the fast-food consumers are making an informed choice because they are aware of both the deficiencies and potentially harmful effects of such food and drinks.

A man is a reasonable and conscious being but sometimes makes choices contrary to reason and consciousness. A good example is the consumption of tobacco products. The consumers of tobacco products are consciously ignoring all the information on potentially lethal harmfulness of tobacco, which is impossible not to know as that information is dominantly displayed on the packaging of those products. A part of the reasons why people consume tobacco products is the addictiveness of nicotine, but that should be a reason more to avoid it, and not the justification for consuming it. It is similar to unhealthy food. We have mentioned that the British government introduced an additional levy on added sugar in soft drinks because of the direct connection of that with obesity and other health complications in children.

Media, as we said, have an exceptionally important role in the creation of consciousness of the audience, and as such, they have an enormous influence on dietary habits. Through their programming content, and largely through advertising, media popularize not only fast food and carbonated soft drinks but various unchecked dietetic products whose main function is to compensate for deficiencies created by the accelerated lifestyle and to aesthetically bring people closer to the idealized picture media imprinted in the minds of people through their systematic activity. That creates a certain vicious circle where people first create a problem for themselves by poor dietary choices and then try to remedy that by consuming products that are also potentially harmful, which cannot lead to a good solution.

Food safety culture is inexcusably neglected in the hierarchy of human priorities. When we say it is neglected, we do not try to precisely determine its position within the hierarchy - it is enough to know it is not among the basic ones, and priorities should follow the hierarchy of needs, where physiological needs are on the first level, and safety needs are on second (Maslow, 1943). It logically belongs there, as there is almost no reasonable and conscious being that would say that food safety is not important. When we say food safety, we include both its quality and its usefulness for the health and optimal functioning of the human organism. Generally, safety culture in the contemporary world is an art of living, and food safety culture as its subset should be embedded in the consciousness of every individual.

\section{Conclusions}

The choice of foods and drinks we will bring into our organism is upon each of us. But for that choice to be informed, as well as for many other things, people live in organized social systems, whose one of important roles is to make binding decisions in the best interests of citizens of that social system, as well as to be one step ahead from its citizens in the regulation of potentially harmful matters, both for the society as a whole and 
every individual. In that sense, these social systems must care about public health, which often is a sum of the health of individuals. An individual will always have the right to do whatever he or she pleases, as it is one of the basic human freedoms, but countries and international organizations should at least make the making of unhealthy choices more difficult or expensive. In that sense, the British government set a good example by introducing an additional levy on products with added sugar, and it marks a good beginning of regulation of that field. These measures can be widened to other foods that contain substances harmful to health but do not contain enough nutritional values. The World Health Organization, as an umbrella organization for care about global health, failed in this case as well. International law precedes the local ones, and in that sense, the WHO will reach its potential and its role because of which the whole world finances it only when its recommendations become legally binding for all the member countries. Until then, while everything is on the level of informative recommendations, the world will not have a singular response, nor will it be capable to combat an increasing number of public health challenges brought by the modern society.

\section{Conflict of interests}

The authors declare no conflict of interest.

\section{References}

1. Alkharfy, K. (2011), Food Advertisements: To Ban or Not to Ban? Annals of Saudi Medicine, 31, 567-568, doi: 10.4103/0256-4947.87089 .

2. Bjelajac, Ž., Dukić-Mijatović, M., Dragojlović, J. (2017), Food safety as one of the main preoccupations of a modern man, Economics of Agriculture, 64 (1), 191-204

3. Bjelajac, Ž., Dukić-Mijatović, M., Vojinović, Ž. (2017), Protection of land in the Republic of Serbia and ecological security with regard to strategic and legal frameworks, Economics of Agriculture, 64 (4), 1703-1721

4. Bjelajac Z., Pocuca M., Dukic-Mijatovic M. (2013), Uranium and Dioxin Consequences of Bombing of Yugoslavia in 1999 and Its Impact on the Ecosystem and Human Health, Journal of Environmental Protection and Ecology, 14 (2), 480-492

5. Centers for Disease Control and Prevention, Adult Obesity Facts (2020), https:// www.cdc.gov/obesity/data/adult.html, (May $7^{\text {th }}, 2020$ )

6. Finkelstein, E., Trogdon, J., Cohen, J., Dietz, W. (2009) Annual Medical Spending Attributable to Obesity: Payer- and Service-Specific Estimates, Health Affairs, 28 (S.1), 822-831, https://doi.org/10.1377/hlthaff.28.5.w822

7. Griffith, C., Price, P. (1994) The Mass Media and Food Hygiene Education, British Food Journal, 96 (9), 16-21, doi: 10.1108/00070709410072535

8. Gunter, B. (2016) Food Advertising - Nature, Impact and Regulation, Palgrave McMillan, Cham 
9. HM Revenue \& Customs, Soft Drinks Industry Levy, 2016, https://www.gov. uk/government/publications/soft-drinks-industry-levy/soft-drinks-industry-levy, (May $\left.9^{\text {th }}, 2020\right)$

10. Institute for Public Health of Serbia, The report on Health Safety of Food and Bottled Water in Republic of Serbia for 2018 [in Serbian: Institut za javno zdravlje Srbije, Izveštaj o zdravstvenoj ispravnosti namirnica i flaširanih voda u Republici Srbiji u 2018] http://www.batut.org.rs/download/izvestaji/Godisnji\%20 izvestaj\%20namirnice\%20i\%20flasirane\%20vode\%202018.pdf, (May 5 ${ }^{\text {th }}, 2020$ )

11. Jensen, M. D., Ryan, D. H., Apovian, C. M., Ard, J. D., Comuzzie, A. G., Donato, K. A., Hu, F. B., Hubbard, V. S., Jakicic, J. M., Kushner, R. F., Loria, C. M., Millen, B. E., Nonas, C. A., Pi-Sunyer, F. X., Stevens, J., Stevens, V. J., Wadden, T. A., Wolfe, B.M., Yanovski, S.Z. (2013) AHA/ACC/TOS guideline for the management of overweight and obesity in adults: a report of the American College of Cardiology/ American Heart Association Task Force on Practice Guidelines and The Obesity Society. Circulation, 129 (suppl.2), S102-S138, https://doi.org/10.1161/01. cir.0000437739.71477.ee

12. Jugović, Z., Pecarski, D., Jordović, B., Bugunović, M. (2017) Food Safety, Food Safety and Health, 1st Conference with International Participation - Proceedings, Techical College Čačak, 7-14 [in Serbian: Jugović, Z., Pecarski, D., Jordović, B., Bugunović, M. (2017) Bezbednost hrane, Bezbednost hrane i zdravlje, 1. konferencija sa međunarodnim učešćem - Zbornik radova, Visoka škola tehničkih strukovnih studija, Čačak, 7-14]

13. Kirk, M., Ford, L., Glass, K., Hall, G. (2014). Foodborne Illness, Australia, Circa 2000 and Circa 2010. Emerging Infectious Diseases, 20(11), 1857-1864. https:// dx.doi.org/10.3201/eid2011.131315

14. Končar, J., Grubor, A., Marić, R. (2019) Improving the placement of food products of organic origin on the AP Vojvodina market, Strategic Management, 24 (3), 2432. Retrieved from http://www.ef.uns.ac.rs/sm/archive/2019-3/03-SM2019-3.pdf

15. Lorimer, R. (1998), Mass Communication, Clio, Belgrade [in Serbian: Lorimer, R. (1998) Masovne komunikacije, Clio, Beograd]

16. Nvolve Group, The 8 Elements of Food Safety Culture, 2017, https://nvolvegroup. $\mathrm{com} / \mathrm{blog} /$ the-8-elements-of-food-safety-culture/, (May $9^{\text {th }}, 2020$ )

17. Maslow, A. H. (1943) A Theory of Human Motivation, Psychological Review, 50, 370-396

18. Marinković, V., Sekulić, D. (2016). The motif of stay as a criterion of segmentation of the users of hotel services. Hotel and Tourism Management, 4 (2), 25-35. Retrieved from http://www.htmanagementvb.com/index.php/HITM/article/view/42

19. Počuča, M., Drašković, B. (2015) Altering the use of agricultural into construction land - practice and trends, Economics of Agriculture, 62 (2), 497-511

20. Rather, I., Yin, K. W., Paek, W. K., Lim, J. (2017) The Sources of Chemical Contaminants in Food and Their Health Implications, Frontiers in Pharmacology, 8, 830, https://doi.org/10.3389/fphar.2017.00830 
21. Spyglass Intelligence, Top 12 US Consumer Magazine Publishers: Circulation and Advertising Revenue, 2017, , https://www.spyglassintel.com/visualization-ofcirculation-revenue-for-the-top-12-us-consumer-magazine-publishers/, (May 10 ${ }^{\text {th }}$, 2020)

22. Vuković, P. (2018) The formation and promotion of rural tourist product in the Republic of Serbia, Ekonomika, 64 (4), 81-92. Retrieved from https://www. ekonomika.org.rs/sr/PDF/ekonomika/2018/clanci18-4/7.pdf

23. World Health Organization, Estimating the Burden of Foodborne Diseases, 2015, https://www.who.int/activities/estimating-the-burden-of-foodborne-diseases, (May $\left.9^{\text {th }}, 2020\right)$

24. Wright M., Leach P. (2013) Diagnosing And Improving Food Safety Culture In Food Businesses, Greenstreet Berman, Reading 